Piotr Urbanek ${ }^{*}$

\title{
INTRODUCTION
}

\section{CORPORATE GOVERNANCE IN THE BANKING SECTOR: LESSONS FROM THE FINANCIAL CRISIS}

The financial crisis, symbolized by the collapse of the Lehman Brothers Bank, once again gave rise to discussion about the standards of corporate governance. This has been explicitly included in the preamble to the Shareholder Bill of Rights Act of 2009, adopted by the United States Senate, which states, inter alia, that: "... among the central causes of the financial and economic crises that the United States faces today has been a widespread failure of corporate governance." [The Library of Congress, 2009]. Hawley et al. [2011, p.3] support such opinion arguing that "...the current financial crisis has, as a part of its origins, a variety of corporate governance failures".

However, it seems that such a categorical assessment of the causes of the current crisis is debatable. There are several threads in the current debate on the subject. First, it is emphasized that in the early twenty-first century, in response to pathological practices and corporate crimes occurring in major U.S. and European corporations, major reforms of corporate governance have been undertaken. Among the areas of corporate governance in which far-reaching changes have been introduced one finds: the standards of financial reporting and financial audit, remuneration policy for corporate management, principles for the functioning of company boards, the requirements for high transparency, better protection of the rights of minority shareholders, the guidelines for institutional investors, the new regulations relating to the corporate market control, and many others. These changes have created a solid foundation which has significantly raised the quality of intra-corporate relationships and improved the functioning of the external market governance mechanisms. Such corporate governance reforms have fostered attitudes towards enhancing accountability and responsibility. In this context, the implementation of existing standards may be the most important issue of the efficiency of corporate governance.

*University of Lodz 
There are also opinions that the new standards and institutions of corporate governance developed in this period have proved ineffective in face of the threats that have emerged in the financial services sector. They ask: Why have financial institutions turned out to be resistant to the new regulations of corporate governance? How did it happen that, in light of the financial crisis, banks have been involved as both actors and victims? Why some financial institutions have been deeply affected by the crisis while others have not? The reforms of early in this century were based on the assumption that the new mechanisms of governance should be versatile enough that their application should extend to all corporations, regardless of their specific characteristics and the sector in which they operate. The crisis has shown that they are not suitable for the control and monitoring of the new business model of banks, where risk management and corporate governance are becoming key factors and governance efficiency should be assessed to a greater extent from the perspective of the financial stability of the sector as a whole than from the perspective of the efficiency of the institutions within the sector.

There are also more radical views [Sun et al. 2011, p.4]. The proponents of this approach believe that the weaknesses of corporate governance lie not only in the fact that existing effective standards are not properly implemented and are not adapted to the sector's specificity, but that the current financial crisis and the failure of corporate governance prove a fundamental systemic failure of the paradigms of the invisible hand of market and of the visible hand of management. If this statement is correct, one should restore some basic foundations of market economy, such as shareholder primacy, profit maximization, rational self-interests of human behaviour, efficient markets for corporate control, etc.

In our opinion the second view in the above debate is the most reasonable. New standards of corporate governance have effectively reduced inefficient business practices occurring earlier in the largest corporations. At the same time, one can point to several factors that have hindered or prevented their implementation in the financial sector institutions. An important cause of dysfunction of governance has been the lack of precision of many standards, which made it possible for the financial institutions to interpret them too broadly. Often, the use of the standards was only of a purely formal nature and lacked the methods to assess their actual implementation. The responsibility of the institutions supervising and monitoring the financial markets with respect to their implementation of the standards has not been specified. In many countries, the new standards of corporate governance have not taken the form of normative acts, mandatory for all entities, but rather the form of recommendations of international institutions and sectoral regulations - codes of good practice - applicable only to public companies. Above 
all, there were no provisions designed specifically for the financial sector, especially for banks, i.e. no provisions which would take into account the specific nature of corporate governance in the banking sector.

This was the result of many factors: systemic risk, the scale and nature of operations, relationships between entities in the banking sector, innovative financial instruments, the complex ownership and control structure in large financial groups, and rapid changes in the business models of financial institutions. The "agency problem" found in private corporations concerns, in the case of banks, the specific relationships and conflicts of interest between shareholders and depositors. This creates an additional dimension when compared to other corporations, because banks are institutions of public trust. The relationship between the entities of the financial sector and the complex ownership and control structures in large financial groups increase the systemic risk associated with the operations carried out in the banking sector. One consequence is that the market mechanism of corporate governance, involving the removal of inefficient entities by the mechanism of mergers, acquisitions, and bankruptcies, is less effective in the case of large financial institutions. Another distinguishing feature of governance in the banking sector is the duality of the roles of banks, which may at same time be shareholders and lenders for the same entities. This can lead to a situation where the interests of banks, as lenders, are contrary to the interests of other shareholders and companies. The specificity of corporate governance in banks is also conditioned by the very nature of the banking business. This is reflected in the components, structure, and risk of banks' assets, as well as in the sources of their funding.

One can identify many areas of banks' operations in which gaps in the procedures of corporate governance became particularly evident. These include: remuneration policy for managers, supervision performed by the boards of banks, passive shareholders, and the activities of credit rating agencies. There are relationships between these areas, but the dysfunctionalities associated with risk management constitute the most important bond that unites them. Risk management in banks determines their economic results and their chances for commercial survival and development.

The key issues include constant identification, assessment, measurement, and monitoring of risks. Risk management is so important in managing banks that the solution to this problem cannot be limited to the internal bank procedures that make up the internal mechanism of corporate governance. Legal and environmental standards, set by international institutions supervising the financial sector and by national regulators, should constitute a complementary mechanism supporting the risk management process. 
The book you are holding in your hands can be regarded as a voice in the debate about the search for effective standards of corporate governance in the banking sector. Its dominant theme is the current financial crisis, presented primarily from the perspective of developments in the financial markets and the consequent implications for efforts to reform corporate governance mechanisms. Particular attention is devoted to the analysis of corporate governance in the Polish banking sector, which was among the least affected by the global financial crisis. The financial stability of Polish banks was not threatened and direct intervention by the state was not necessary. There was no loss of confidence in the financial market, which could have resulted in liquidity problems. This relatively good situation of the Polish banking sector raises the natural question about the causes which led to its position. If one of the main causes of the current crisis was banks' failure to comply with the principles of corporate governance, it seems interesting to assess the quality of supervisory procedures applied by Polish banks.

The book consists of nine chapters. In the first chapter Cz. Mesjasz and W. Rogowski define the concept of financial stability in terms of key research issues in the book. As they point out "... it is commonly agreed that relatively unambiguous and precise definitions and interpretations of the concept of financial stability have not been elaborated yet ...". And further that "It may be treated as a paradox that so many institutions and people emphasize the significance of the term, which is so poorly defined ...". The authors do not usurp the right to effectively fill in this research gap. At the same time they conclude that "...the definitions (of financial stability) can be decomposed into dimensions reflecting characteristics of the markets and criteria of their assessment, characteristics of the institutions and criteria of their assessment, and relations between the markets and the institutions - norms and activities...". Such an approach can significantly facilitate the examination of the relationships between different concepts of financial stability and corporate governance.

A new regulatory tool, which is beginning to play an important role as a factor stabilizing the financial system, is so-called 'soft law', i.e. codes of good practice. E. Klepczarek indicates in her article that soft law instruments are commonly used in business practice and have a significant impact on the functioning of entities in the financial system. Codes of good practice contribute to systematizing, organizing and clarifying requirements in terms of ethics, enhancing mutual trust between market participants. In this way they enforce the use of higher standards in services rendered by the banks. In addition to the many advantages of this regulatory solution, her article also highlights the risks involved with it, including in 
particular the use of them as a purely an image-building move rather than a real attempt to implement pro-consumer attitudes.

The systemic failure in the supervision of banks, exposed by the current financial crisis and ensuing attempts to reform the system, form the subject of M. Marcinkowska's considerations in the chapter on the new corporate governance in banking. She adopts the thesis that "... the financial system is as strong as its governance practices, the financial stability of its institutions, and the effectiveness of its market infrastructure. The creation and application of good governance practices is the joint responsibility of market regulators and market participants..." This indicates that the core elements of an improved, stable and responsible financial system should include an effective regulatory regime, which must be supported by high management standards and values as a part of banks' corporate culture.

This research topic is continued by $\mathrm{K}$. Misiołek in the subsequent paper. He examines corporate governance in banks from two perspectives. First, banks are public institutions which require effective legal, institutional, and customary foundations. But modern banks also take into account in their actions the social and financial models of corporate operations. These models must be followed by proper organizational structures and procedures, supported by an adequate corporate culture ensuring appropriate standards and by incentives for professional and responsible conduct, which is essential for good governance.

Executive compensation policy in the financial sector institutions is often regarded as one of the key factors that led to the current financial crisis. The systemic dysfunctions in financial corporations revealed by the current financial crisis have shown the need for far-reaching reforms. In the subsequent chapter of this monograph, A. Słomka-Gołębiowska compares recent recommendations of international organizations to regulate executive pay in the financial services industry with legal initiatives introduced in Poland. In the second part of her article she assesses whether the new legal rules have a significant impact on the structure of the executive compensation in Polish public banks.

The independence of supervisory board members is an institutional solution which significantly affects the executive compensation policy in banks. The obligation to appoint such persons to serve on the board results from, among others, codes of good practice. A. Wieczorek analyzes the extent to which the banking companies listed on the Warsaw Stock Exchange (WSE) observe the regulations concerning the appointment of independent supervisory board members. She also tries to determine whether the independent board members are appropriately educated and have the proper qualifications to perform their tasks on supervisory boards. 
There are two key features of the Polish banking sector. First, ownership and control of banks in Poland are very concentrated, and second, most banks are controlled by foreign strategic investors which are owned by global financial groups. K. Postrach raises the question, formulated in the next paper, whether the current ownership structure of banks operating in Poland is beneficial for the Polish economy and whether there is an alternative solution to this situation. $\mathrm{He}$ concludes that, "... it would be advisable to request relevant institutions (the Polish Financial Supervision Authority, the National Bank of Poland, and the government) to increase the share of locally controlled banks in the assets of the Polish banking sector. This process can be described as the domestication of banks."

One of the major causes of bankruptcies is dysfunctions in ownership supervision, including insufficient use of an early warning system. Business practice provides a lot of evidence in this regard, but the latest international financial crisis is a real laboratory, full of examples of the lack of such supervision. P. Masiukiewicz indicates in his article that receivership management is an effective legal and managerial tool for the rehabilitation of banks, but regulations in this field are insufficient in Poland.

The last chapter of the book presents the main bank system, which determines relationships in the process of corporate governance between companies and institutions in the financial sector in Japan. M. Jerzemowska in her article points to the origins and main characteristics of this specific institutional arrangement, which differs substantially from the Anglo-American model. The confrontation of these two different models of corporate governance does not lead to a clear-cut assessment concerning which of them ensures better efficiency of corporate governance.

The book that we would like to recommend to you refers to current developments observed in both the Polish and global economy. It is one of the first titles on the Polish market dedicated to assessment of the role of mechanisms of corporate governance in the banking sector. These developments increase the need for reliable, systematic knowledge on the subject. We hope that the articles in this book illustrate, in an original way, many of these developments. Where it was not possible to formulate clear assessments and answers, the threads elaborated in this book may be a valuable contribution to further in-depth discussion between academia and business. 


\section{References}

1. Hawley, J.P., Kamath, S.J., and Williams, T. 2011, Corporate Governance Failures. The Role of Institutional Investors in the Global Financial Crisis, University of Pennsylvania Press, Philadelphia.

2. Sun, W. Steward, J. , and Pollard D. 2011. Corporate Governance and the Global Financial Crisis. International Perspectives, University Cambridge Press.

3. The Library of Congress 2009. Shareholder Bill of Rights Act of 2009, S. 1074. 